\title{
Impact of Quality of the Work Life on Job Involvement in the Institutions of the Palestinian Public Sector
}

\author{
Salameh Mohamad Walid Salem and Olfat M. N. Abu Jarad \\ Department of Business Administration, Faculty of business Science and Economics, Alquds Open University, Palestine
}

\begin{abstract}
The main objective of this study is to supply executives with data about the needs of employees towards better job involvement. The researchers used the descriptive survey method for the purpose of the study .To achieve the objectives of the study, the researchers used the questionnaire as a study tool which they developed themselves and consisted of (30) items, and distributed on two levels, after ascertaining validity . To answer the questions of the study, the researchers adopted various statistical tests (T- test, ANOVA, and OLS method). For the analyzing process, means, standard deviation, and result of multiple regression of the quality of work life upon job involvement among employees were used in the study. According to the results of the study and the statistical analysis of the questionnaire ,the researchers recommend that incentive and rewarding policy should be adopted in those institutions to applaud workers for more achievement and superiority, and Preparing other studies and researches to study other factors that affect job involvement that are not involved in this sample.
\end{abstract}

Key Words: Quality of work life, job involvement, Palestinian public sector

\section{Introduction}

The work life is a compound system of the whole environment around the employee such as equipments, work team, and enhancement tools to name but a few, and provided that all establishments and organizations yearn to gain the best out of each employee to fulfill their aims in having Creative job; they should offer qualified work life that can lead to employees' minimum satisfaction, and employee's involvement in many cases causing prosperous situation for the work place.

Within the bad situation of Palestinian establishment, stated by the report of the team of strengthening Palestinian authority establishments in 2003, and the serious pressure from the interior and international parties on the authority executives to do the required reform in various aspects of Palestinian life either politically or economically, the researchers found it worthy to follow up employees work life in those communities and establishments; and whether they gained the improvements they yearn to have in the system they belong to in their work places or not, in order to accomplish some of the report recommendations related to the reform needed to overcome the tough circumstances around employees (Al Shaqaqi, Khalil et al., 2003).

The researchers found their study to be one of the rare studies that went through that situation.
Though the economic situation suffers a lot in Palestinian governorates, maintaining a rewarding working atmosphere for employees to work effectively is an urgent necessity to challenge reality and create comfortable circumstances of life, so the researchers have found it beneficial to go through some data about the situation of employees in Tulkarm public sector establishments and whether there is a high quality of work life, physically and mentally, that may lead to employees' job involvement or not (exe.)

\section{Purpose of the Study}

Psychologically speaking, humans need a rewarding atmosphere that motivates them to be creative and effective at their work, so quality of work life in various aspects as health safety, cooperative co workers, reasonable care of employee's needs and development, satisfying salaries and comfortable work place are vital things to be offered if we seek job involvement among employees that leads to effectiveness and

Corresponding author: Salameh Mohamad Walid Salem Department of Business Administration, Faculty of business Science and Economics, Alquds Open University, Palestine, Email: smsalamah@qou.edu

(c) This article is distributed under the terms of the Creative Commons Attribution License, which permits unrestricted use and redistribution provided that the original author and source are credited. 
efficiency which in its turn will improve the whole economic view in our establishments and solve many financial problems. As a result of that, the researchers wanted to attract attention to the necessity of high quality of work life for employees in public sector of Tulkarm as it plays a vital role in development in working environment in Palestine.

\section{Statement of the Problem}

This study aimed to investigate Tulkarm public sector employees' point view in the extent of work life quality at their work places, in addition to grasping a clear scene about job involvement in a trial to share as possible as we can to supply public sector executives with information needed to make all required improvements.

\section{Objectives of the study}

The study's main objective is to survey Palestinian public sector institutions' employees' point view in the extent of quality of their work life and its impact upon job involvement. The sub objectives are 1- to supply public sector directors with additional data about needs of employees towards better job involvement in their establishments.

2- to motivate decision makers to get benefit from other experiences where there is high quality of work life and hence distinctive job involvement through workers, and try to imitate these experiences for better job situations.

\section{Questions of the study}

The study aimed to answer these questions:

1- To what extent are Tulkarm public sector institutions provide quality of work life in work place?

2- what's the relationship between quality of work life and employees' job involvement?

\section{Hypothesis of the study}

The study has two main hypothesis that are divided into sub hypothesis, these are:

The first main hypotheses (H1): "There is no statistically significant relationship between work life quality and job involvement in Palestinian public sector institutions"; it is branched into these sub-hypothesis:

(H1.1): "There is no statistically significant relationship between the criteria "morals at work" for work life quality and job involvement in public sector institutions.

(H1.2): "There is no statistically significant relationship between the criteria "work team" for work life quality and job involvement in public sector institutions.

(H1.3): (There is no statistically significant relationship between the criteria "salaries and rewards" for the work life quality and job involvement.

(H1.4): "There is no statistically significant relationship between the criteria "supervision method" for the work life quality and job involvement.

(H1.5): "There is no statistically significant relationship between the criteria "participation in decision-making" for the work life quality and job involvement.

The second main hypotheses" The null hypotheses (H0)

"There are no significant differences at $(\boldsymbol{\alpha} \leq 0.05)$ in Palestinian public sector institutions' employees' attitudes towards the importance of the work life upon job involvement due to: experience years, academic level, and gender variables". It is branched into these sub-hypothesis:

(H0.1): "There are no statistically significant differences at $(\boldsymbol{\alpha} \leq 0.05)$ in Palestinian employees at public sector institutions attitudes towards the impact of the work life quality upon job involvement due to gender variable.

(H0.2) "There are no statistically significant differences at $(\boldsymbol{\alpha} \leq 0.05)$ in Palestinian employees at public sector institutions attitudes towards the impact of the work life quality upon job involvement due to academic level (qualifications) variable.

(H0.3) "There are no statistically significant differences at $(\boldsymbol{\alpha} \leq 0.05)$ in Palestinian employees at public sector institutions attitudes towards the impact of the work life quality upon job involvement due to years of experience variable.

$(H 0.4)$ " There are no statistically significant differences at $(\boldsymbol{\alpha} \leq 0.05)$ in Palestinian employees at public sector institutions attitudes towards the impact of the work life quality upon job involvement due to position at work variable.

\section{Research Methods}

The present study will follow the methodology which was followed by most of the studies that have analyzed the relationship between quality of work life and employees' job involvement. In the first place a wide range of library survey is conducted to review the administration literature related to quality of work life and employees' job involvement and to draw a solid theoretical framework to the study. While in the second place, an econometric model is proposed to testify the variables that represent factors of quality of work life and employees' job involvement in Palestine; this model will depend on a three multi regression equations in which the effect of the varia- 
bles of the study can be assessed by using the official data of the Palestinian Central Bureau of Statistics (PCBS).

The researchers used the descriptive survey method for the purpose of the study. The population of the study consisted of all male and female Tulkarm public sector institutions who were (9000). The questionnaire was applied to the total sample of (311) employees.

To achieve the objectives of the study, the researchers used the questionnaire as a study tool which they developed themselves and consisted of (30) items, and distributed on two levels, after ascertaining validity. To answer the questions of the study, the researchers adopted various statistical tests such as (T-test and ANOVA) . For the sake of analyzing results, means, standard deviation, and result analysis of multiple regression dimensions of the quality of work life upon job involvement among employees were used in the study.

\section{Literature Review}

In a study conducted by (Davy, et al, 1997), and examined the effect of job security on workers as one of the standards of work life, it was found that employees' job security is positively related to the employees' well beings; and dissatisfaction of the employees may result in the turnover of employees. Trying to state for the manager role in maximizing job involvement (Hebert et al,2011) stated that the manager must take advantage to utilize the available knowledge and opportunities generation to maximize the ability of people and knowledge management through the adequacy of resources and facilities." Things that are considered vital criteria for quality of work life.

Forward to the important corporation of "organizational culture" in job involvement then job success,( Giles, 2000) said that the culture must be used as strong strategic tool for the betterment and improvement of organizational environment. He added that on the job, success is ensured if the individual working habit matches the organizational culture. A new conception that can be taken into consideration in other local studies.

Through investigating job commitment's stimulations ,(Agarwal, et al, 1999)along with( Smith, 2013) have found that if the employees are committed with the organization, then organizations use their human resources as the competitive edge through job rotation, mentoring and training programs.

A study by (Mehdipour, et al,2012) that addressed the relationship between the quality of working life and job involvement of Iranian physical education teachers, showed that in order to increase job involvement of physical education teachers, it is important that the Iranian educational authorities and executives endeavor to ensure efficient organization of school physical education courses in standard conditions and with maximum facilities, through research and efficient planning.

By calling the $21^{\text {st }}$. century "the century of quality" Joseph Juran's considered the efficiency and quality of work life (QWL) to be the most dominant factors affecting the organizational function (Tracy MD, 2006).

Koedphol (2007) led us to some factors that affect the quality of work life which one: age, gender, academic degree, position and income. A study that met with the researchers in two of these factors: academic degree, and position.

To investigate the relationships between the (QWL) and the tendency to stay on a specific job, Beikpour et al. conducted a study that found a positive and significant relationship between the (QW L) and the organizational commitment as well as the tendency to maintain the job.

Empowerment of employees, group work, and apprenticeships are demonstrated to be ways to increase the job involvement level according to a model by Boon and Kurtz (2005). They also clarified the term empowerment as a process in which employees are given the authority to make decisions associated with their own work, without being externally with. (Permarupan et al,2013) examined the relationship between the quality of work life (QWL), employees' job involvement and affective commitment among the employees of the public and private sector organizations, opportunities at work and climate organization had a relatively higher impact on "job involvement" and "affective commitment" rather than "fair and appropriate salary", and "capacities at work".

Taylor and Cosenza, (1998) highlighted the employees' interest nowadays in elevating both their quality of life and quality of work life, which exceeded the importance of money at the same side. A study that supports the researchers' choice of "work place moral conditions as a criteria of quality of work life". Fine's (1998) assured the importance of quality of work life by saying that people are social attachment.

A point view that certifies that being highly involved in the job is often a response to emotional rather than rational needs.

"a construct which deals with the well being of employees." In that way QWL was described by( Lee et al, 2007), in an appointment for its importance in job involvement.

Other study on organizational commitment (OC) of employees has identified three types of (OC) which are: affective, continuance, and normative (Allen and Meyer, 1997). 
A study by Kanungo (1982) found that an employee who is highly motivated towards the job renders better involvement to the organization than those who are not. Hyun (2009), pointed out that as a result of globalization that has affected all aspects of life, among them is economy, South Korea has made an effort to change the environment of the workplace; creating a government that works better and costs less. Consequently, they stressed the people resources of government must be valued more highly and developed more carefully. Freund, (2005) found that job involvement and commitment have each received attention as work-related attitudes and subsequent predictors of work-related outcomes. As stated by Wikipedia, (Baba and Jamal, 1991) listed what they described as typical indicators of quality of working life job satisfaction, job involvement, work role am- biguity, work role conflict and others, they also explored reutilization of job content, suggesting that this facet should be investigated as part of the concept of quality of working life. It can be clear of the related literature that all previous studies have pointed out to the distinctive importance of maintaining high quality of work life for employees to have remarkable job involvement and commitment; and that is the same finding of this study also.

\section{The Study Sample}

The sample of the study consisted of public sector employees in Palestinian governmental communities. It was chosen randomly in order represent the whole society of the study which has been determined. According to the following equation (Moore et.al. 2003).

$$
\mathrm{n}=\left(\frac{z}{2 \times m}\right)^{2}
$$

Where $\mathrm{z}$ : value (class) standard corresponding to the significance level of 0.95 which is equal to 1.96 significance level (0.05) $\mathrm{M}$ : the error margin expressed as a decimal mark (eg: $0.05 \pm$ )

$$
\mathrm{n}=\left(\frac{1.96}{2 \times 0.05}\right)^{2}=384 \mathrm{n}
$$

The correct sample size in the case of the final communities of the equation is: Amended (2) $n=\frac{n N}{N+n-1}$

Whereas: $\mathrm{N}$ : the sample size of the unadjusted $\mathrm{N}$ : community size $\mathrm{N}$ : revised sample size

$$
n=\frac{384 \times 9000}{9000+384-1} \quad \mathrm{n}=386
$$

And so the appropriate size of the sample in this case equals 386 items, and the regular random sample was used. After assuring the reliability of the questionnaire and making the required revisions,(386) questionnaires were distributed, where (368) of them were back to the researchers ; which means $(4.1 \%)$ of the whole community(9000), in Palestinian public communities ; in order to guarantee the return of the utmost number of them and increasing trust in results, as (311) of them were received, $(84.5 \%)$ of the real sample, which means that 57 $(3.5 \%)$ were neglected.

\section{Results}

The study aims to identify the impact of the quality of work life upon job involvement in Palestinian public sector communities, in addition to identifying the effect of: gender, scientific qualifications, experience and position. After collecting data, it was treated sta- tistically by (Statistical package for social science (SPSS). The results of the study were as follows:

One sample $\mathrm{T}$ test was used to analyze the questionnaire items. The positive item means: the sample individuals responds positively on its content; as calculated(t)is greater than critical $(\mathrm{t})$ which means that sig. is less than $(0.05)$ and the relative value is $(60 \%)$ or more ,then the level required is the measurement 3 or more ,whereas the negative item means : the sample individuals responded negatively on its content if calculated $(\mathrm{t})$ is less than critical $(\mathrm{t})$ which means that sig. is greater than (0.05) and the relative value is less than $60 \%$ and the level required is the measurement which is less than 3). Firstly, Results related to the study main question: What is the effect of the quality of the work life in Palestinian public communities on employees' job involvement? To answer this question, means, standard deviation, $t$ test, and sig for each item and the total degree for the questionnaire were used. 
Table 1. Mean and Stranded deviation

\begin{tabular}{|c|c|c|c|c|c|c|}
\hline $\begin{array}{l}\text { Item } \\
\text { no. }\end{array}$ & $\begin{array}{l}\text { Quality of work life in Palestinian public sector and its impact } \\
\text { upon workers' job involvement }\end{array}$ & Mean & St.d & $\%$ & $\mathrm{~T}$ test & sig \\
\hline 1 & $\begin{array}{l}\text { The business atmosphere in the institution where I work is } \\
\text { featured by mutual trust }\end{array}$ & 3.72 & 0.96 & $74.40 \%$ & 13.14 & $0.000 *$ \\
\hline 2 & I have positive relationships with my colleagues at work & 4.22 & 0.61 & $84.40 \%$ & 35.27 & $0.000 *$ \\
\hline 3 & I feel respect by others in the institution where I work & 4.20 & 0.58 & $84.00 \%$ & 36.24 & $0.000 *$ \\
\hline 4 & I am satisfied with my accomplishments at my work & 4.09 & 0.78 & $81.80 \%$ & 24.87 & $0.000^{*}$ \\
\hline 5 & I am satisfied with my salary & 3.00 & 1.19 & $60.00 \%$ & 0.01 & 0.99 \\
\hline 6 & My salary is suitable for the amount of work accomplished & 2.86 & 1.15 & $57.20 \%$ & $2.22-$ & $0.027 *$ \\
\hline 7 & Salaries and rewards system is fair and efficient & 2.50 & 1.09 & $50.00 \%$ & $8.09-$ & $0.000 *$ \\
\hline 8 & $\begin{array}{l}\text { The institution I work in adopt incentives and rewards to } \\
\text { encourage achievement and excellence }\end{array}$ & 2.32 & 1.12 & $46.40 \%$ & $-\overline{10.72}$ & $0.000 *$ \\
\hline 9 & $\begin{array}{l}\text { The institution allows employees to participate in making } \\
\text {.decisions related to their work }\end{array}$ & 3.27 & 1.03 & $65.40 \%$ & 4.62 & $0.000 *$ \\
\hline 10 & $\begin{array}{l}\text { The institution provides sufficient information that enables me to } \\
\text { actively participate in decision-making }\end{array}$ & 3.20 & 0.90 & $64.00 \%$ & 3.96 & $0.000^{*}$ \\
\hline 11 & $\begin{array}{l}\text { The institution encourages employees to cooperate and participate } \\
\text { in business matters }\end{array}$ & 3.39 & 0.95 & $67.80 \%$ & 7.14 & $0.000^{*}$ \\
\hline 12 & $\begin{array}{l}\text { Participation in decision-making in my institution gives me an } \\
\text { appropriate degree of freedom in the performance of my work }\end{array}$ & 3.47 & 0.93 & $69.40 \%$ & 8.97 & $0.000 *$ \\
\hline 13 & My boss seize any opportunity to involve me in decision- making & 3.60 & 0.94 & $72.00 \%$ & 11.29 & $0.000 *$ \\
\hline 14 & $\begin{array}{l}\text { My boss takes justice and fair into his account while dealing with } \\
\text { employers }\end{array}$ & 3.56 & 1.04 & $71.20 \%$ & 9.50 & $0.000 *$ \\
\hline 15 & I consider my boss's style in management as an incentive one. & 3.55 & 0.97 & $71.00 \%$ & 9.91 & $0.000^{*}$ \\
\hline 16 & My boss at work has a great ability in fore planning for work & 3.58 & 1.01 & $71.60 \%$ & 10.08 & $0.000 *$ \\
\hline 17 & I feel that I am an important part of the team in the institution. & 3.87 & 0.91 & $77.40 \%$ & 16.97 & $0.000^{*}$ \\
\hline 18 & $\begin{array}{l}\text { Every person in my team has thoughtful understanding of business } \\
\text { objectives. }\end{array}$ & 3.60 & 0.97 & $72.00 \%$ & 11.02 & $0.000 *$ \\
\hline 19 & The members of my team have integrated experiences. & 3.70 & 0.89 & $74.00 \%$ & 14.03 & $0.000^{*}$ \\
\hline 20 & Team members participate in decisions related to their work. & 3.62 & 0.93 & $72.40 \%$ & 11.83 & $0.000 *$ \\
\hline \multicolumn{2}{|r|}{ Total degree } & 3.47 & 0.60 & $69.40 \%$ & 13.62 & $0.000 *$ \\
\hline
\end{tabular}

Critical T when sig. $(\alpha \leq 0.05)(2) *$ : sig. $(\alpha \leq 0.05)$

One sample t test was used as shown in table (1) ,which represented sample's individuals attitudes towards items related to work life quality's criteria (non material standards, represented by (1-4) items of the questionnaire, salaries and rewards represented by (5-8) items , employees' participation in decisions making represented by (9-12) items, supervision method represented by items (13-16), work teams represented by (17-20); it was clear that the item : ( I have positive relationships with my colleagues at work) and (non material standards at work) was the best to be responded on positively by $(84.40 \%)$, which means the response for it was positive, a fact that is determined by stating that it was significant as critical $t$ is (35.27) which is greater than critical $(t)$ which equal (2) and sig. (0.000); which is less than $(0.05)$. That refers to the fact that public sector employees have strong relationships together as they live close to each others and have other relationships than the job one as neighborhood, relativity, study fellowships, in addition to sharing the same circumstances imposed by Israeli occupation. On the other hand, the item that represented the highest negativity was ; ( The institution I work in adopt incentives and rewards to encourage achievement and excellence) and (salaries and rewards criteria) by $(46.40 \%)$ which means that the response was negative but has a significance as calculated (t) was (10.72-) which is greater than critical $(\mathrm{t})$ which was (2-) with a significance $(0.000)$ which is less than $(0.05)$; in other words, the respondents responded highly negatively on this item so ,its response was less than the proposed mean by 3 degrees, or less than the relative weight $(60 \%)$. The researchers refer that to the low income level for the employee in the public sector; which doesn't meet their basic needs. Moreover, Palestinian public sector communities suffer regularly from salaries stop because of the Israeli keeping for Palestinian taxes income and can't, therefore, adopt incentives policy for employees as rewards and oth- 
ers. Generally speaking, we can interfere that : mean for items of ( work life quality in public sector communities criteria and its impact upon job involvement ) is (3.47), relative value is $(69.40 \%)$ which is greater than neutral relative value $(60 \%)$, calculated $(\mathrm{t})$ is (13.62) which is greater than critical (t) (2) , sig. is $(0.000)$ which is less than (0.05) which means that : ( There is an impact of work life quality upon job involvement among the natural limitations which reflects employees' feeling of job security in public sector as it is governmental employment ; stable and permanent.
Secondly: testing the first main hypothesis (there is a statistically significant effect of the five dimensions of the field of the quality of work life on job involvement for employees in the Palestinian public institutions).

The hypothesis was tested by analyzing multiple regression equation for the criteria of quality of work life and their impact upon job involvement for employees of public sector institutions in Palestine. Analyses results were as shown below:

Table 2. Results analysis of multiple regression dimensions of the quality of work life upon employees' job involvement

\begin{tabular}{|l|l|l|l|l|}
\hline Independent variables & $\beta$ & Standard error & T.Test value & Sig \\
\hline Constant quantity & 1.18 & 0.247 & 4.79 & $0.000^{* *}$ \\
\hline Non material conditions at work & 0.421 & 0.071 & 5.97 & $0.000^{* *}$ \\
\hline Salaries and rewards & 0.098 & 0.057 & 2.49 & $0.013^{*}$ \\
\hline Participation in decision-making & $0.043-$ & 0.058 & $0.75-$ & 0.46 \\
\hline Supervision method & 0.003 & 0.061 & 0.05 & 0.96 \\
\hline Work team & 0.224 & 0.039 & 3.66 & $0.000^{* *}$ \\
\hline $\mathrm{F}-$ Statistics & 26.827 & & 0.562 & \\
\hline $\mathrm{R}^{2}=0.305$ & Adjusted $\mathrm{R}^{2}=0.294$ & $\mathrm{r}=0.552$ & & $0.000^{* *}$ \\
\hline
\end{tabular}

Table (2 shows) estimation results of multiple regression equation according to the (OLS) method. Results can be interpreted as follows:

- It was found that criteria of work life quality that affect the dependent variable(job involvement) are:

- Non material conditions, work team, salaries and rewards whereas the impact of participation in decision making and supervision method was weak .Therefore, multiple regression line equation for job involvement is :

Job involvement $=1.180 .42 \times$ moral conditions at work $+0.098 \times$ wages and rewards $+0.22 \times$ working group - $0.043 x$ participate in decisions $+.003 x$ supervision method.

According to this equation, results of this test can be interpreted as follows:

- The test has proved the positive impact of (moral conditions at work) variable upon workers' job involvement in Palestinian public institutions, as the parameter value of this variable is $(0.421)$ and so, the improvement of work moral conditions for workers in Palestinian public institutions by (\%1) results in a positive impact upon job involvement for workers by (0.421), this impact was determined by $(\mathrm{t})$ test as calculated $(\mathrm{t})$ was (5.97) which had a sig. (1\%)
- There is also a positive impact for (work team) variable upon job involvement in Palestinian public institutions, as the parameter value of this variable is (0.224) ,and so motivating work teams and harmony among them by (\%1) leads to a positive impact of job involvement in that institutions by $(0.224 \%)$, and $(\mathrm{t})$ test determined that as calculated (t) was (3.66) which had a statistical significance at level (\%1).

- There is also a positive impact for (wages and rewards) variable upon job involvement in Palestinian public institutions, as the parameter value of this variable is (0.098), and so increasing wages and rewards by (\%1) leads to a positive impact of job involvement in that institutions by $(0.098 \%)$, and $(\mathrm{t})$ test determined that as calculated $(\mathrm{t})$ was (2.49) which had a statistical significance at level (\%5).

- There is also a weak positive impact for (supervision method) variable upon job involvement in Palestinian public institutions, as the parameter value of this variable is $(0.003)$, and $(t)$ test determined that as calculated $(\mathrm{t})$ was not statistically significant as calculated $(\mathrm{t})$ hasn't reached to the significance level and it was (0.05) which is not statically significant. 
- Finally, results have shown a negative relationship between (participation in decision-making ) variable and job involvement, and it is not statistically significant as shown by (t) test in which $9 \mathrm{t}$ ) hasn't reached to significance level, the parameter value was $(-0.043)$, which means that there is a conflict between this result and the administrative and theoretical situation between the two variables.

- The researchers refer these results to the presence of a positive relationship between variables by relatively accepted rates according to the very recent Palestinian experience in administrating public institutions, especially that Palestinians have had the control on these institutions for the first time after (OSLO) treaty in (1994) ; an experience which was exposed to breakdown in the initial of forming Palestinian authority for its concepts in public institutions . After twenty years of the emerge of Palestinian authority, a remarkable improvement on the administrative performance has been seen as a result of the experience during that time, in addition to the benefit from other regional and international countries experiences ,especially Europeans and Americans ones through technical support programs and counseling offered for Palestinian Authority.

- The results related to the variables (supervision method and participation in decision making) were weak and negative according to the nature of the work of public institutions that is administered by (centralism and hierarchy), and so the workers' re- sponses on the items of these variables were opposing. They also negated any participation for them by their managers in decisions, in addition to their being incapable to make any changes and being severely observed by their bosses, all have led to those results.

- (f) test has shown the validity of the sample used, as the statistical sig. of the sample was proved and calculated (f) was (26.8) which is significant at (\%1).

- The determination coefficient $\mathrm{R}^{2}=(0.305)$ points to the ability of the independent variables of this sample to interpret (\%30) of the change in the dependent variable (job involvement) which means that (\%70) of the change in job involvement relates to other reasons and factors that are not involved in the sample that was tested. The researchers concluded that the null hypotheses should be rejected to have the alternative hypotheses accepted, that is, (there is a statistically significant impact for the five criteria of the work life quality upon workers' job involvement.

- Thirdly, the second main hypotheses that is related to the independent variables of the study.

- Results related to the first sub hypotheses : (There are no significant differences $(\alpha \leq 0.05)$ for the impact of work life quality upon workers' job involvement in Palestinian public institutions according to gender variable.

- To examine this hypotheses, independent (t) test was used, results are shown in table (3)

Table 3. T test results for the impact of the quality of work life upon job involvement

\begin{tabular}{|c|c|c|c|c|c|}
\hline \multicolumn{2}{|c|}{$\begin{array}{c}\text { Male } \\
\text { No. }=174\end{array}$} & \multicolumn{2}{c|}{$\begin{array}{c}\text { Temale } \\
\text { No.=137 }\end{array}$} & \multirow{2}{*}{ Sig. } \\
\cline { 1 - 3 } mean & St.d & mean & St.d & & \\
\cline { 1 - 4 } 3.47 & 0.64 & 3.46 & 0.55 & 0.15 & 0.88 \\
\hline
\end{tabular}

Critical ( $\mathrm{t}$ ) at the significance level $(\alpha \leq 0.05)(1.96)$

It is clear from table (3) that calculated $(\mathrm{t})$ was $(0.15)$ which is less than critical $(\mathrm{t})$ which means that there are no statistically significant differences at $(* * 0.05)$ in the impact of work life quality upon job involvement in Palestinian public institutions according to gender variable, so we adopt the null hypotheses that there are no significant differences.
2- Results related to the second sub hypotheses :( there are no statistically significant differences at $(\alpha \leq 0.05)$ in the impact of work life quality upon job involvement in Palestinian public institutions according to qualifications variable.To examine this hypotheses one way ANOVA was used. Table (4) shows (means) while table (4.1) shows results of ANOVA. 
Table 4. Means for the impact of the quality of work life upon job involvement

\begin{tabular}{|l|l|l|}
\hline $\begin{array}{l}\text { Diploma or less } \\
\text { No. }=56\end{array}$ & $\begin{array}{l}\text { BA. } \\
\text { No. }=196\end{array}$ & $\begin{array}{l}\text { MA. Or above } \\
\text { No. }=59\end{array}$ \\
\hline 3.45 & 3.42 & 3.63 \\
\hline
\end{tabular}

Table 4.1. Results of ANOVA for the impact of work life quality upon job involvement

\begin{tabular}{|c|c|c|c|c|c|}
\hline Source of variation & $\begin{array}{c}\text { Degrees of } \\
\text { freedom }\end{array}$ & Total square deviation & Average deviation & F value & \multirow{2}{*}{2.74} \\
\cline { 1 - 3 } Between groups & 2 & 1.978 & 0.989 & \multirow{2}{*}{0.07} \\
\hline Within groups & 308 & 111.148 & 0.361 & \\
\hline Total & 310 & 113.126 & & \\
\hline
\end{tabular}

Critical (f) at the significance level ( $\alpha \leq 0.05)$ (3:02)

Table (4.1) shows that calculated (f) was (2.74), this value is less than the critical value (3.02), that is: There are no statistically significant differences at ( $\boldsymbol{\alpha} \leq \mathbf{0 . 0 5}$ ) in the impact of work life quality upon job involvement in Palestinian public institutions according to qualifications variable, so we adopt the null hypotheses stating no significant differences.

(3) the results of the third sub-hypotheses, there are no statistically significant differences at the level of significance $(\alpha \leq 0.05)$ for the impact of the quality of work life upon job involvement in Palestinian public institutions according to years of experience variable.

To test the hypothesis, one way ANOVA was used. Table (5) shows (means) while table (5.1) shows results of ANOVA

Table 5. Means for the impact of the quality of work life upon job involvement

\begin{tabular}{|l|l|l|}
\hline From 1- 5 & From 6 -10 & More than 10 years \\
No. $=68$ & No. $=67$ & No.=176 \\
\hline 3.59 & 3.41 & 3.44 \\
\hline
\end{tabular}

Table 5.1. Results of ANOVA for the impact of the quality of work life upon job involvement

\begin{tabular}{|c|c|c|c|c|c|}
\hline Source of variation & $\begin{array}{r}\text { Degrees of } \\
\text { freedom }\end{array}$ & $\begin{array}{l}\text { Total square } \\
\text { deviation }\end{array}$ & Average deviation & F value & Sig. \\
\hline Between groups & 2 & 1.327 & 0.664 & \multirow{3}{*}{1.83} & \multirow{3}{*}{0.16} \\
\hline Within groups & 308 & 111.799 & 0.363 & & \\
\hline Total & 310 & 113.126 & & & \\
\hline
\end{tabular}

Critical (f) at the significance level $(\alpha \leq 0.05)(3: 02)$

Table (5.1) shows that calculated (f) was (1.83), this value is less than the critical value (3.02), that is: There are no statistically significant differences at $(\alpha \leq 0.05)$ in the impact of work life quality upon job involvement in Palestinian public institutions according to years of experience variable ,so we adopt the null hypotheses stating no significant differences.
(4) the results for the fourth sub hypothesis:( there are no statistically significant differences at the level of significance $(\alpha \leq 0.05)$ for the impact of the quality of work on the job involvement in Palestinian public institutions according to position variable.

To test the hypotheses, one way (ANOVA) test was used. Table (6) shows (means) while table (6.1) shows results of (ANOVA) test 
Table 6. Means of the impact of the quality of work life upon job involvement

\begin{tabular}{|c|c|c|}
\hline $\begin{array}{c}\text { employee } \\
\text { No. }=171\end{array}$ & $\begin{array}{c}\text { Head of department } \\
\text { No. }=99\end{array}$ & $\begin{array}{c}\text { manager } \\
\text { No. }=41\end{array}$ \\
\hline 3.44 & 3.50 & 3.52 \\
\hline
\end{tabular}

Table 6.1. Results of ANOVA for the impact of the quality of work life upon job involvement

\begin{tabular}{|c|c|c|c|c|c|}
\hline Source of variation & $\begin{array}{c}\text { Degrees of } \\
\text { freedom }\end{array}$ & $\begin{array}{c}\text { Total square } \\
\text { deviations }\end{array}$ & Average deviation & F value & Sig. \\
\hline Between groups & 2 & 0.325 & 0.162 & \multirow{2}{*}{0.44} & \multirow{2}{*}{0.64} \\
\hline Within groups & 308 & 112.802 & 0.366 & & \\
\hline Total & 310 & 113.126 & & & \\
\hline
\end{tabular}

Critical (f) at the significance level ( $\alpha \leq 0.05)(3: 02)$

Table (6.1) shows that calculated (f) was (0.44), this value is less than the critical value (3.02), that is: There are no statistically significant differences at $(\alpha \leq 0.05)$ in the impact of work life quality upon job involvement in Palestinian public institutions according to position at work variable ,so we adopt the null hypotheses stating no significant differences.

It is clear from hypotheses analysis results for the independent variables related to personal features for the sample items (gender, qualifications, years of experience, position at work) that they are no significant, which means the acceptance of the null hypotheses. The researchers refer that to their exposure for the same conditions, regulations, and procedures of work that are totally centralized regardless their personal features; this fact was interpreted by multiple regression analysis as there is a relatively accepted level for work life quality criteria upon job involvement; these criteria have interpreted (\%30) from the whole factors and there are others affecting involvement by (\%70).

\section{Conclusions}

After analyzing questions and hypotheses of the study, it was inferred that:

- The whole level of work life quality in Palestinian public institutions according to the sample items responses was $(69.40 \%)$, which means that there is a fair impact for work life quality upon job involvement in Palestinian public institutions.

- The sample items responses on (salaries and rewards ) especially that is related to item (b) ( The institution's adoption of fair salaries and rewards system that encourages achievement and superiority), were less than the neutral relative value as it is (46.40),which means that they eagerly opposed that item which is not existed in our institutions.

- The sample items responses showed that the relationship that is between workers is highly positive as infered from its level (84.40).

- There is a relatively fair relationship between work life quality and job involvement which enhances the need for efforts to the motivation of quality criteria in that institutions.

- Results show that the impact of (moral conditions of work, and participation in decision making ) is low upon job involvement since our public institutions are ruled by centralism, and work according to herareichal organizing.

- Finally, the study has shown that work life quality criteria (moral conditions of work, salaries and rewards, work team, participation in decision making, and supervision method) that are chosen in this sample have interpreted (\%30) form the change in job involvement; and (\%70) of this change in job involvement in public institutions refers to other reasons not mentioned in this sample.

\section{Recommendations}

The researchers recommend the following in the light of the mentioned findings:

- Incentive and rewarding policy should be adopted in those institutions to applaud workers for more achievement and superiority.

- Building a new insight for salaries and wages in public institutions that may guarantee a furious and fair life for workers. 
- Increasing workers' participation in decision making especially in matters that relate to them.

- Trying to decrease the depend on centralism in decision making and supervision method and moving towards non centralization as possible .

- Supplying enough data for workers about their work in a way that fulfill a bit of empowerment in order to do their tasks appropriately.

- Preparing other studies and researches to study other factors that affect job involvement that are not involved in this sample.

\section{References}

Agarwal, R. and T. Ferrat ( 1999).Coping with labour scarcity in IT: Strategies and practices for effective recruitment and retention, pinnaflex : Cincinnati. $\mathrm{OH}$.

Allen, J \& Meyers, J.P (1997). The Measurement and Antecedents of Affective, continuance and Normative Commitment to the organization. Journal of Occupational Psychology,63, 1-18.

Beikpour o, Hosseini M. (2012). Relationship between the quality of work life and with job involvement and job maintenance tendency. Master's thesis (Persian).Edited by Mehdipour et al.

Carmeli A (2005) Exploring determinants of job involvement , an empirical test among senior executives. Int $J$ Manpower, 26(5): 457- 472.

Davy, J. ,A. Kinicki and C. Scheck, (1997), A test of job security 's direct and mediated effects on withdrawal cognitions, Journal of Organizational Behavior,18, 323- 349).

Freund, A.(2005). Commitment and Job satisfaction as predictors of turnover intentions among welfare workers. Administration in social work, 29 (2), 5-21.

Giles, R. (2000). Identifying and influencing organizational culture. Retrieved from: http:// www.alliesconsulting .com/resources/articles/idinflcult.html.

Hebert, p. and S. chaney,( 2011). Enhancing facilities management through generational awareness ,Journal of Facilities Management, 9 (2),145- 152.

Hussain et al. (2014). Do employees' job satisfaction, involvement and commitment mediate relationship between quality of work life and employees' retention?, World Applied Sciences Journal, 30(2),245-252, Pakistan.

Hyun, Ha-Young (2009). Analysis the Factors impact on the Job involvement and Organizational Commitment, Korea University.
Kanungo, R.N (1982). Measurement of job and work involvement. Journal of Applied Psychology, 67(3), 341-449.

Koedphol P (2007). Relationship between personal factors, quality of working life and job performance of professional nurses in private hospitals. A thesis submitted in partial fulfillment of the requirements for the degree of Master of Nursing Management, Mahidol University.

Lee, D., Singhapakdi, A., \& Sirgy, M.J. (2007). Further validation of a Need-based Quality-of-work-life (QWL) measure: Evidence form Marketing Practitioners. Applied Research in Quality of life, 2(4),273-287.

Mehdipour et al.(2012), Relationship between the quality of working life and job involvement of Iranian physical education teachers, studies in physical culture and tourism ,19(4),2012,185-190.

Permarupan. P et al . (2013). Quality of work life on Employees job involvement and effective commitment between the public and private sector in Malaysia, Asian social science; 9(7).

Smith, S (2013). Employee satisfaction survey questions: 3 sample templates you can use today. For more see: https://www.qualtrics.com/blog/customer-satisfactionsurvey-questions

Tayler, S.L, \& Cosenza, R.M. (1998). Reducing turnover in public accounting firms: An International Marketing Strategy, 17 (2).135-147.

Tracy MD,( 2006). The Relationship Between Emotional Intelligence and Job Satisfaction: Testing the Claim that Emotional Intelligence Quotient Predicts level of Job Satisfaction, doctoral dissertation, Capella University.

Baba, VV and Jamal, M (1991) Routinisation of job context and job content as related to employees quality of working life: a study of psychiatric nurses. Journal of Organisational Behavior. 12. 379-386. https://en.wikipedia.org/wiki/Quality_of_working_life

Mafini et al , (2014). The Relationship between Extrinsic Motivation, Job Satisfaction and Life Satisfaction Amongst Employees in a Public Organisation, SA Journal of Industrial Psychology. http://dx.doi.org/10.1007/s11482-008-9042-x

Colbert, Amy E, et al (2004) Interactive Effects of Personality and Perceptions of the Work Situation on Work Place Deviance . American Psychology Association. Vol 4. http://dx.doi.org/10.1111/j.20448325.1990.tb005x06..

AL Shaqaqi and Sayegh, (2003). Palestinian Establishments Reform: What is New? For more see: www.cfr.org/content/publications/attachments/5536_a rabic.doc 